\title{
Analysis of Organizational Silence Attitudes of Hotel Operations' Employees by Structural Equation Model: Examplary of Rize Province
}

\author{
Ali Caglar Gulluce, Asst.Prof. \\ Atatürk University, Open Education Faculty \\ Eren Erkilic, Instructor \\ Recep Tayyip Erdoğan University, Ardeşen Vocational School
}

doi: 10.19044/esj.2016.v12n19p9 URL:http://dx.doi.org/10.19044/esj.2016.v12n19p9

\begin{abstract}
The objective of this research is to be able to identify the organization silence attitudes of the employees working at the hotels being operated in the city of Rize. For this purpose, questionnaire was applied to 228 employees functioning at the hotels. The data obtained have been analyzed with LISREL program. As a result of confirmatory factor analysis oriented towards determining the organizational silence behaviors of those who have taken part in the survey, favorable significant differences have been identified among the factors of organizational silence behavior. In this context, it has been determined that the most effective variable of "I think that my managers would not listen to my ideas" at a rate of .84 on the factors of Managerial and Organizational Reasons; at a rate of .83 on the factor of the Work - Related Topics "Public speaking can lead to loss of my job" variable; at the rate of .84 on the factor of Lack of Experience of "Since my position I am in is a lower level, my notification of an idea is disregarded" variable; at a rate of .84 on the factor of Isolation Factor "Reporting an issue may reduce confidence and respect felt to me" and at a rate of .87 on the factor of Fear Regarding Harming the Relationships "When I tell the problems, my relationships are damaged" variable. In addition, it has been observed that the Work - Related Topics factor had an influence at the rate of .93 between the factors of Fear of Isolation and Fear of Damaging the Relationships and the factors of Lack of Experience and Fear of Damaging the Relationships had an impact at the rate of .93 between each other.
\end{abstract}

Keyword: Organizational Silence, Structural Equation Model 


\section{The Concept of Organizational Silence}

Today, the rapid increase of competition and as a result of development and transformation taken placed in the information technologies, the importance of sharing the information has promoted. Thus the attitude of remaining silent of the employees used to be perceived to be an indicator of harmoniousness in the organizations today, started to be perceived a response or withdrawal (Bildik, 2009, 34; Ozdemir \& Sarioglu Ugur, 2013).

Hirschman (1970) who has associated the concept of silence with the businesses for the first time has evaluated this as an affirmative response and an indicator for remaining connected to the organization (Quoted by Cakic1, 2010, 9). The silence meaning state of staying silent, at the first glance, it is evaluated like being closed to communication though, the studies carried out in recent years has demonstrated that the silence is a type of communication harboring too many feelings and thoughts (Pinder and Harlos, 2001). This concept defined to be "The employees who deliberately do not sharing the work - related issues and information about issues, ideas and concerns with the administration yet saving the same for themselves" has been firstly suggested as a threat by Morrison and Milliken (2000, 706-725) for the development and transformation of the organizations. The organizations - to be able to survive under varying competition - expect the employees to clearly demonstrate the behavior of clearly express their knowledge, opinions and ideas about the organization (Bowen \& Blackman, 2003; Premeaux, 2001; Quinn \& Spreitzer, 1997). Nevertheless, the organizations cause the employees to show sometimes intentionally, sometimes unintentionally behavior of remaining silent (Soycan, 2010). The studies have shown that the employees have not participated in the discussion and explained their idea seven they had the self - confidence (Premeaux \& Bedeian, 2003, 1539-1562).

\section{Loudness, silence and organizational silence}

Dyne, Ang and Botero (2003) have explained the concept of silence of the employees to possess organization's development - oriented ideas, knowledge and constructive opinions. The concepts of voice and silence are the antonyms of each other. While the voice is being defined as the expression of what is known by the individual and the silence, being the exact opposite hereof may be expressed as saving this by the person for herself / himself for various reasons (Sarikaya, 2013). When the literature was scrutinized, it is seen that the concept of silence was caused to be giving by different disciplines such as psychology and sociology (Oruc, 2013). Having the concept of silence associated with the organizational structure for the first time, Albert Hirschman (1970) has used the word silence in its book 
called "Exit, Voice and Loyalty" as a synonym for the term passive but constructive and loyalty. Later on, its use as a synonym with the loyalty has been kept on in this way for a while and researches have been carried out in this direction (Bryant \& Cox, 2004, 578-592). Afterwards, it has started to be addressed as an active, conscious, purposeful and affecting the performance of organization (Cakıc1, 2010, 9; Ruclar, 2013).

In the literature, it may be talked about two fundamental studies revealing it with its current meaning by removing the organizational silence from its meaning of traditional approval and silence in the literature (Morrison \& Milliken, 2000; Pinder \& Harlos, 2001). Morrison and Milliken (2000), they address the organizational silence which they describe that the employees save their thoughts related to the development of organization deliberately as the "collective phenomena" posing an obstacle to the development of the organization. As for Pinter and Harlos (2001), in their study in which they proposed a model explaining the factors which revealed the organizational silence led to their strengthening, they have described this concept as a response to unfair practices in the organization. Also in the studies carried out later on, silence, in studies it has been made of many different definitions of organizational silence has been made. Van Dyne et al., (2003), in their studies where they have developed a measuring tool in order analyze the reasons of employees who stayed silent; they have defined this concept as the employees who do not disclose their organizational topic - related opinions. Similarly, Bowen and Blackmon (2003) have also defined it as the situation of employees who do not make contribution to the organization where they work by not disclosing their business - related opinions. According to Henriksen and Dayton (2006), it is a fact that employees speak little regarding business - related matters which might be solution the organizational problems or exhibit little attitude. As for Slade (2008, 50), he has evaluated the organizational silence to be a common behavior shape in which the employees do not speak of their case - related feelings and thoughts when they are encountered with any problem from the institution. The common point of definitions made in the above-mentioned two basic studies and the definitions made in the subsequent studies related to organizational silence is in general non-expression of information and ideas intentionally and being limited by organizational issues and problems (Barcin, 2012, 7; Oruc, 2013; Ruclar, 2013).

Jensen (1973) has stated that the silence has five each twin functions (Quoted by Pinder \& Harlos, 2001, 338):

1. Silence does not only cause people to gather but also gets them away from each other.

2. Silence does not only cause harm on the relationship among people but also improves it. 
3. Silence does not only provide the information but also conceals it.

4. Silence does not only mean deep thinking but also no thinking.

5. Silence does not only mean agreement but also disagreement.

When the literature is reviewed, it is seen that the studies related to organizational dimension of the silence are relatively new and limited (Beheshtifar, Borhani \& Moghadam, 2012, 276; Bowen \& Blackmon, 2003; Erenler, 2010, 8). Even though its effect on the organizations is very big, the fact that the researcher have exhibited this much late interest to the subject and the researches related to the topic have not been sufficiently accomplished have been linked to the causes such as the silence has difficulty in being analyzed and an exact consensus on the concept has failed to be reached and its difficulty in being understood and interpreted (Van Dyne et al., 2003, 1364). Similarly Milliken and Morrison (2003, 15641568) have also stressed on that the concept of silence is a concept which can be based on very distinctive causes and is difficult to be understood and interpreted.

With different studies carried out, distinctive factor which have led to emergence of silence behavior have been set forth. Under this attitude, it has been seen that the feelings like belief of talking about organization - related topics could be dangerous and social exclusion (Freire, 1970; NoellaNeumann, 1974) and uselessness (Morrison \& Milliken, 2000; Van Dyne et al., 2003) lied (Kostiuk, 2012, 30-31). Once the feelings and thoughts of this nature gained prevalence in the organization, the climate of silence occurs. When a climate of silence become dominant in an organization, namely the fact that the employees who do not share their ideas and thoughts related to the organizational matters and prevent different thoughts and perspectives to be set forth turn into a major obstacle for transformation, development and therefore even its success (Morrison \& Milliken, 2000, 707). The behaviors such as negligence of issues emerged and staying unresponsive against the issues hinder the knowledge and opinions of employees regarding institution - related issues to come to life by being filtered with the negative feedbacks of the employees. As a result of hereof, organizational development may be adversely affected (Morrison \& Milliken, 2000; Premeaux, 2001). The situation of a negative organizational silence is not only likely to be observed on the organization but also on its employees. Whereas the individuals remain silent on a subject already known by them, they may be drifted by the feelings like impotence and feeling herself/himself worthless. It can be said that even the senses of organizational commitment, loyalty, trust, appreciation, support, motivation and job satisfaction are adversely affected from this situation (Cakıc1, 2010, 4; Detert \& Edmondson, 2005; Milliken \& Morrison, 2003; Ruclar, 2013). 


\section{Types of Organizational Silence}

Base on distinct causes, the behavior of silence emerging in different forms from the organizations has been divided by Dyne et al., (2003) into three classes; accepting silence, defensive silence and protectionist silence.

\section{Accepting silence}

Being from the types of silence, the accepting silence is the case where the individuals accept the current situation and do not share any ideas and thoughts to change it. Once the individual thought that her / his ideas would not be deemed valuable and even if she/he had shared them, they would not constitute any difference or felt herself / himself incapable, She / He would accept the current situation and her / his interest felt to the case would reduce thus, begin exhibiting the attitude of silence (Dyne et al., 2003, 1366). In other words, the accepting silence is the fact that the individuals accept current situation and do not make any efforts to change it due to thinking that their organization - related issues - oriented feelings and ideas would not pose any influence on the decisions to be taken.

\section{Defensive silence}

This type of silence is that the employees who get scared of the results they think they would come across when they shared their feelings and ideas keep them concealed in order to protect themselves (Pinder \& Harlos, 2001). Some of the studies carried out have revealed that one of the essential factors why the individuals remain silent was the sense of fear (Dyne et al., 2003, 1367; Morrison and Miliken, 2000). This sense of fear leads to the concealment of the thoughts of employees about the problems (Dyne et al., 1366). Since an individual think that she / he would undergo hardship once she / he shared her / his idea her / his manager would not like to hear, as a strategic conduct, she / he may prefer staying silent in order to protect her / his image, credit and position (Milliken \& Morrison, 2003).

\section{Protectionist silence}

This type of silence is non-disclosure of knowledge, opinion and ideas regarding certain matters depending on thinking of others and cooperation for the benefits of organization and other employees (Podsakoff, Mackenzie, Paine \& Bachrach, 2000). The silence of this nature differs from other types of silence in terms of an employee staying silent because of causes other than herself / himself like the benefit of organization or other employees (Dyne et al., 2003). 


\section{Types of Staying Silent}

The attitude of staying silent exhibited by the employees may demonstrate itself in distinctive forms from the organizations. The patterns of remaining silent may be grouped in form of obedience, deaf ear syndrome, remaining passive and withdrawing and going for other behaviors of the employee.

\section{Employee obedience}

Generally speaking, the obedience is to accept current conditions without questioning existing situation. The silence behavior may result from the obedience of individual (Bildik, 2009, 43). Silence can be an indication of what people consciously and voluntarily agreed the current situation without objection (Hirschman, 1970). The persons of this nature believe in the necessity of regulations and rules from the organization. They may tolerate present situation more easily and be less stressful in comparison to other employees. The obedient employees become less aware of their silence (Bildik, 2009, 43). Although they are unaware, they might be unwilling to be reluctant on the organization - related topics. They are not wishful regarding looking for alternates against present situation (Pinder \& Harlos, 2001, 350-352). They do not feel necessity to think or express their thoughts and ideas on what they could contribute to the organization. And this attitude becomes having hampered emergence of different and various ideas at the organization (Col, 2004, quoted by Yanik, 2012, 47).

\section{Deaf ear syndrome}

Deaf Ear Syndrome also defined to be organizational inertia is the behaviors of employees not to hear and see negative situations they are come across within the organization (Karadal, 2011, 371). It can also be defined to be an organizational norm which prevents them to clearly express dissatisfaction of employees within the organization (Brinsfield, 2009, 75). Among the causes for employees' orientation towards such behavior, it may be said that the thought that they avoid the consequences which might arise when they have expressed their opinions or their expression of ideas would not make any changes underlies (Karadal, 2011, 371). In addition, organizational communication network, the policies organization follows, the concept of organizational climate and organizational justice not having adequately developed may be listed among other caused of deaf ear syndrome (Yanik, 2012, 52).

\section{Staying passive and acceptance}

Some employees in the organization stay silent against illegal, nonethical and unfair attitudes of other employees (Aliogulları, 2012, 22; 
Sehitoglu, 2010, 57). These persons think that their presence in the organization does not bear ant sense and their opinions related to the organizational issues they express would not have any impact on the decisions to be taken, they agree present situation and prefer staying passive (Dynevd, 2003, 1366). For the decisions taken, they appear supporting by nodding or smiling (Sehitoglu, 2010, 57).

\section{Withdrawal and going for other behaviors}

Since the employees are afraid of its negative results, like being punished, not being promoted and dismissal, they withdraw themselves and remain passive and go for the behaviors they deem they would not lead to negative outcomes for themselves (Bildik, 2009, 44; Kahveci, 2010, 19-20).

\section{Constituting Factors of Organizational Silence}

The attitude of organizational silence is a behavior developing in time depending on various reasons (Karadal, 2011, 372). There are too many factors causing organizational silence. From the perspective of organizational development, identification of these factors is substantial. The causes of organizational silence have been grouped by different researchers in different ways. Milliken, Morrison and Hewlin (2003) have grouped these reasons in three headlines; organizational, managerial and individual. The factors leading silence have been compiled under the following titles in this study considering the studies in the literature (Cakici, 2010; Milliken, Morrison \& Hewlin, 2003; Premeaux 2001; Pinder \& Harlos, 2001).

\section{Managerial and organizational reasons}

In a study Cakici and Cakici (2007, 399) has accomplished in the Republic of Turkey, they have concluded that the managerial and organizational silence was one of the most crucial factors pushing the employees to the attitude. Whereas the managers are the persons making decisions, setting down the policies and rules of the organization, they have a substantial impact in development or non-development of silence from the organization (Cakici, 2010, 63). In an organization where an approach of management that is not open for different ideas is adopted, the attitude of employees to demonstrate the behavior of silence is an expected outcome. While the individuals functioning in such an environment think that notification of their opinions would not have any effects, they also think that whenever they notify any opinions or idea the managers do not want to hear, they would draw reaction of them and this would be risky from the aspect of them as well. And therefore, they prefer keeping quite (Milliken, et al., 2003, 1466-1473). 
And another factor for the employees to remain silent is that they do not trust their managers. The studies show that there is a positive relation between the managers - oriented distrust and employee silence. Because, when the employees do not trust their managers, in order to protect themselves, they prefer presenting their knowledge to their managers by filtering it (Liu, Wu \& Ma, 2009, 1648). In this context, exhibition of organization benefit - oriented attitudes by the employees is closely associated with the fact that they trust their managers by seeing them to be the representatives of the organization (Arslantas, 2008, 111).

As defined in Mc Gregor's $x$ theory, the managers whose negative thoughts about their employees like "They want to sneak out of work at every opportunity and think of their own interests and are lazy and unreliable" and their believes they have in mind that solely they know the best at all times may lead to the employees to become silent and this turns into a common behavior in the organization (Taskiran, 2011, 88-89). In contrast, the employees may consider their managers possessing the power as a threat in terms of their own development and advancement. This situation leads to avoidance of sharing their knowledge they think that their managers would not be pleased by an obstacle of communication between the employees and the managers (Ercelik, 2008, 109). According to the employees, particularly lack of management, decision making process, inequality in wages, the weakness of organizational inefficiency and organizational poor performance are the subjects which explicitly entail remaining silent (Ryan \& Oestreich, 1991, quoted by Morrison \& Milliken, 2000, 706-707 ).

It is seen that some organizational structures and the balance of power and rules orient them towards the behavior of remaining silent by decreasing their tendency of sharing their information (Argyris, 1977). The hierarchical structure of an organization allowing only communication from top to bottom and do not backup communication from top to bottom prevents open communication between managers and employees. At the organizations possessing this type of hierarchic organizational structure, it has been seen that the employees avoided giving information about the problem in the organization and even when they had to make this, they preferred communicate such problem by simplifying it (Rafferty \& Restubog, 2011, 272). In contrast, the tendency of employees from the organizations enjoying a horizontal and team - based organizational structure in communicating the problems to their superiors higher (Huang, Vilert \& Van der Vegr, 2005).

\section{Fear of isolation}

One of the most essential causes in emergence of the behavior of staying silent is the fear of being rejected and staying alone experienced by 
the persons (Sarioglu, 2013). Once the employees are encountered with the fear of exclusion, they select one of the behaviors; either expressing their thoughts or staying silent. And in most cases, they exercise their preference towards the attitude of staying silent (Scheufele \& Moy, 2000). The persons would prefer not to share their opinions they deem that it would not receive and support by other employees or put the opinions matching with the opinion of the majority and dishonest view into words (Cakici 2007, 153). They are always in struggle of discovering what the opinion of majority is and the popularity of which opinions has promoted while the popularity of which opinions decreased (Cakici, 2010, 154). The cause hereof is the fact that they are afraid of being labeled to be a trouble-maker and in consequence hereof, being likely to be isolated (Milliken and Morrison, 2003, 1565).

\section{Fear of damaging relations}

Since the employees do not want to be considered as a trouble making person from the organization or think that they would be seen as a finger man when they talked about a negation related to an employee and the relationship between that people would be damaged, they may prefer remaining silent. They think that when they talked about present situation, it would not create any difference in current situation and moreover they might be encountered with the problems like losing their jobs, lack of promotion and the like (Milliken et al., 2003, 1462). In addition to this, in order to prevent their friend to get encountered with a negative result or with the opinion that she / he could make the same mistake later on, the persons do not put a negativity related to their about colleagues into words (Cakici, 2010, 22-23). Kahveci $(2010,15)$ suggests that the fear of damaging the relations emanates from the persons who fail to sufficiently understand each other as a result of lack of communication.

\section{Speech deemed risky}

Employees think that participation in the organization - related arguments are risky. The persons believe that expression of the problems would not only have any influence but also this would lead to negative outcomes for them (Asfold, 1998, quoted by Morrison and Milliken, 2000, 707). Therefore, even on the matters they have self-confidence, they may prefer remaining silent (Ryan \& Oestreich, 1998, quote by Premeaux \& Bedeian, 2003, 1537).

Even though the silence from the organizations is a commonly observed behavior, it is a hard to research subject as it related to the behaviors of the individuals which cannot be observed directly (Johannesen, 1974, quoted by Fletcher \& Watson, 2007, 157). Once the pertinent literature 
is scrutinized, it is seen that this concept was not adequately investigated (Bowen \& Blackmon, 2003, 1393-1417). There exists organizational silence concept - focused studies in the literature though (Huang, Van de Vliert and Van der Veght, 2005; Premeaux \& Bedeian 2003), it can be said that there is not adequately "empiric evidence" related to the main components of this concept (Cakici 2010, 2). Despite that the persons show the attitude of staying silent due to distinctive reasons, as they may exhibit such behavior due to common reasons, investigation of the factors causing the silence is important. In this context, the relationship between the factors causing organizational silence has been analyzed with the structural equation model in this study.

\section{Material and Method Structural Equation Models}

Observable and unobservable structural equation models (SEM) particularly (latent) variables used to test the causal relationships between (latent) variables is a comprehensive statistical technique in the dependent and in the independent variables as well. It has been proven that it is a useful technique in solution of the problems encountered concerning formulation of conceptual structures as well. It is a systematic tool used especially in evaluation of relationship between the variables of psychology, sociology, marketing and education sciences and for testing theoretical models. Technically, SEM is used in the estimation of unknown parameters in the linear structural equation set. Variables in the equalities are generally latent variables directly observed and associated latent variables. SEM assumes presence of a causality structure between the latent variables set and the latent variables can be measured through observed variables (Yilmaz and Celik, 2005).

Structural Equation Model (SEM) is a statistical modeling technique and reveals the cause - effect relationship between measureable and nonmeasureable variables. Structural Equation models comprise many analysis techniques which are more powerful in comparison to many analysis techniques like multiple regression, path analysis, factor analysis, time series analysis and covariance analysis and the methods being alternate thereto (Sehribanoglu, 2005).

In 1989, Bollen states that there are mainly three components in the historical trend of structural Equation modeling, these are: (a) path analysis, (b) conceptual synthesis of structural model and measuring and (c) overall estimation processes. The casual models has shown the confirmatory factor analysis (CFA), (Confirmatory Factor Analysis - CFA) and structural equation modeling. Modern SEM is originally known as JKM (Joreskog Keesling - Wiley) model. But later on, upon development of LISREL being 
the first ready-to-use software in 1973, it has been called to be "Linear Structural Relationship Modeling (LISREL)’, (Yilmaz and Celik, 2009).

SEM includes one or more than one linear regression equations illustrating how the internal structures are connected to external structures. They are named as coefficients, path coefficients or mostly regression weighers. When making SEM modeling, the following stages are accomplished;

a) To develop a theoretical model,

b) Drawing a diagram showing the casual relations for developed model,

c) To convert drawn diagram into structural and measurement models,

d) To estimate and evaluate the structural model,

e) To calculate the compliance measurements for structural model,

f) To interpret the results (Sahin, et al., 2008).

\section{Method}

In the study, as data collection method in survey research techniques were used. Variable to be used after a literature review on the subject of research has tried to determine the scale of the structures in order to establish the best possible way. In order to set forth best variable to be used following the literature screening on the subject of the research, the scales are tried to be determined. Therefore, 28 questions have been employed consisting of 5 dimensions for the purpose of determine whether or not participant show the behavior of organizational silence. To measure the organizational silence, the scale developed by Cakici and Cakici (2007) and used by Soycan has been utilized. To measure the dimensions of managerial and organizational reasons in the scale of organizational silence are contained in (12 articles), (5 articles) business - related topics, lack of experience (4 articles), fear of isolation (4 articles) and fear of damaging relations (3 articles).

The poll form drawn up has been applied to 280 employees randomly selected among the hotel employees operating in the city of Rize in 2014. The sample size has been calculated with Ozdamar (2001)-proposed unlimited universe $(\mathrm{N}>10,000)$ and $\mathrm{n}=\sigma^{2} Z_{\alpha}^{2} / H^{2}$ formula for quantitative researches. The survey questions are in 5 - Likert style (1. Never, 5. Always). After deduction of survey forms filled in wrong or incomplete by some of the employees, the analysis has been actualized over valid 228 survey forms.

Cronbach's Alpha value being the reliability constant for the overall of the articles contained in the questionnaire used has been calculated as .949 that this value is the indicator that the survey is reliable. 
Table 1. Demographic Characteristics of Hotel Employees

\begin{tabular}{|c|c|c|c|}
\hline Factor & Category & Frequency & Percentage \\
\hline \multirow{3}{*}{ Gender } & Male & 92 & 40.4 \\
\cline { 2 - 4 } & Female & 136 & 59.6 \\
\hline \multirow{4}{*}{ Age } & Under 20 & 21 & 9.2 \\
\cline { 2 - 4 } & $21-25$ & 68 & 29.8 \\
\cline { 2 - 4 } & $26-30$ & 55 & 24.1 \\
\cline { 2 - 4 } & Over 30 & 84 & 36.8 \\
\hline \multirow{4}{*}{ Education } & Primary school & 41 & 18.0 \\
\cline { 2 - 4 } & Secondary school & 101 & 44.3 \\
\cline { 2 - 4 } & Undergrad & 81 & 35.5 \\
\cline { 2 - 4 } & Master's Degree & 5 & 2.2 \\
\hline \multirow{4}{*}{ Civil Status } & Married & 116 & 50.9 \\
\cline { 2 - 4 } & Single & 108 & 47.4 \\
\cline { 2 - 4 } & Other & 4 & 1.8 \\
\hline \multirow{5}{*}{ Department } & Front Desk & 78 & 34.2 \\
\cline { 2 - 4 } & Food-Bevereage & 71 & 31.1 \\
\cline { 2 - 4 } & Housekeeping & 50 & 6.9 \\
\cline { 2 - 4 } & Sales \& Marketing & 15 & 6.1 \\
\cline { 2 - 4 } & Accounting & 14 & 31.1 \\
\hline \multirow{5}{*}{ Year at Work } & Less than 1 year & 71 & 43.0 \\
\cline { 2 - 4 } & Between 1-5 years & 98 & 15.8 \\
\cline { 2 - 4 } & Between 6-10 years & 36 & 10.1 \\
\cline { 2 - 4 } & More than 10 years & 23 & \\
\hline
\end{tabular}

$40.4 \%$ of the survey participants consisted of men and $59.6 \%$ hereof was women. According to Table - 1, and while $9.2 \%$ of the employee were below the age of $20,29.8$ was in the age group of $21-25,24.1 \%$ was in the age group of $26-30$ and $36.8 \%$ was above 30 years. Once the educational statuses of employees were examined, $18 \%$ of the employees were elementary school, 44.3\% high school, 35.5\% university and 2.2\% Master's degree. As the civil status, $59.9 \%$ of the survey participants were married and $47.4 \%$ was single.

$34.2 \%$ of the survey participants were working at the front office department, $31.1 \%$ in the food and beverage department, $21.9 \%$ housekeeping, marketing and sales of $6.6 \%$ sales and marketing departments and $6.1 \%$ at the accounting department. In addition, $31.1 \%$ of employees has been working at the hotel operations for a period less than one year, $43 \%$ between $1-5$ years, $15.8 \%$ between $6-10$ years, $10.1 \%$ is more than 10 years. 


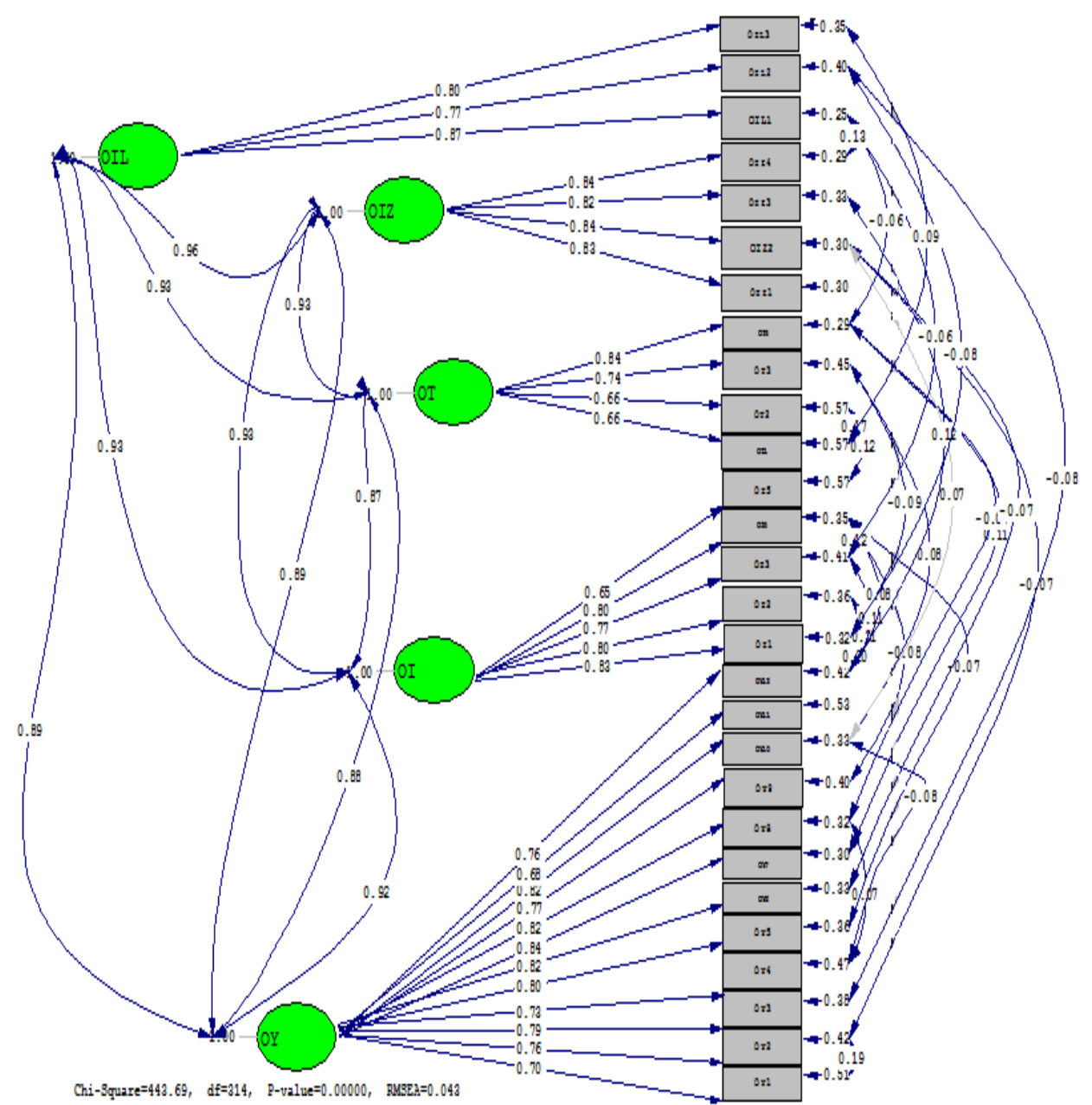

Figure 1 Confirmatory Factor Analysis Results Showing Organizational Silence Status of Hotel Employees

Table 2. Compliance Criteria Values pertaining to the Established Model

\begin{tabular}{|c|c|c|c|}
\hline $\begin{array}{c}\text { COMPLIANCE } \\
\text { CRITERIA }\end{array}$ & $\begin{array}{c}\text { EXCELLENT } \\
\text { COMPLIANCE }\end{array}$ & $\begin{array}{c}\text { ACCEPTABLE } \\
\text { COMPLIANCE }\end{array}$ & MODEL \\
\hline RMSEA & $0<\mathrm{RMSEA}<0.05$ & $0.05 \leq \mathrm{RMSEA} \leq 0.10$ & 0.061 \\
\hline NFI & $0.95 \leq \mathrm{NFI} \leq 1$ & $0.90<\mathrm{NFI} \leq 0.95$ & 0.980 \\
\hline NNFI & $0.97 \leq \mathrm{NNFI} \leq 1$ & $0.95 \leq \mathrm{NNFI} \leq 0.97$ & 0.990 \\
\hline CFI & $0.97 \leq \mathrm{CFI} \leq 1$ & $0.95 \leq \mathrm{CFI} \leq 0.97$ & 0.990 \\
\hline GFI & $0.95 \leq \mathrm{GFI} \leq 1$ & $0.90 \leq \mathrm{GFI} \leq 0.95$ & 0.900 \\
\hline AGFI & $0.90 \leq \mathrm{AGFI} \leq 1$ & $0.85 \leq \mathrm{AGFI} \leq 0.90$ & 0.850 \\
\hline
\end{tabular}

(References: Schermelleh-Engel and Moosbrugger, 2003: 36)

In Figure - 1, five factors and variables found with the scale of organizational silence and the correlation between each other has been shown. Once Figure - 1 was looked through, OY represents the dimension of "Managerial and Organizational Causes of the organizational silence 
behavior, OI “Work Related Issues”, OT “Lack of Experienced”, OIZ "Fear of Isolation" and OIL "Fear of Damaging Relations". Nevertheless, OY1, OY2, OY3, OY4, OY5, OY6, OY7, OY8, OY9, OY10, OY11, OY12 represent the dimensional variables of managerial and organizational causes; OI1, OI2, OI3, OI4, OI5 variables of work related issues; OT1, OT2, OT3, OT4 variables of lack of experience; OIZ1, OIZ2, OIZ3, OIZ4 variables of fear of isolation and OIL1, OIL2, OIL3 variables of fear of damaging the relations.

In this context, once Figure - 1 was scrutinized, a 1 - unit increment of OY1 variable "I do not tell my problems since I do not trust my manager" has a positive - oriented effect at the rate of .70 with dimension of (OY) managerial and organizational causes. A 1 - unit increment of OY5 variable "My managers do not support my clearly speaking" at the rate of .80; A 1 unit increment of OY6 variable "I know the best attitude of my managers makes my speaking meaningless” at the rate of .82; A 1 - unit increment of OY7 variable "There is no formal mechanism that will allow me to speak clearly," I think that my manager would not listen to my ideas" at the rate of .84. In Figure -1 , it has been seen that 1 unit increase of variables in the dimension of managerial and organizational causes has a positive versatility effect between rates of .68 and .84 .

On the other side, a 1 unit - rise in the variable of OI1 "clearly speaking can lead to lose my job" has a positive versatility effect in dimension of work-related issues (OI) at the rate of .83. A 1 unit - rise in the variable of OI2 "when I notify a problem and issue, my job space and position may change" at the rate of .80; A 1 unit - rise in the variable of OI5 "new ideas and proposals may promote my work load" at the rate of .65.

Once Figure - 1 was examined, a 1 unit - rise in the variables of OT1 "I do not have adequate experience to notify an issue or make a proposal" and OT2 "the topics and issues related to my workplace and job interest the management, not me” has a positive versatility effect at a rate of .66 in dimension of (OT) lack of experience. In addition, while a 1 unit - rise in the variables of OT3 "the matter I express can reveal my ignorance and inexperience" has an effect at a rate of .74 in dimension of (OT), a 1 unit rise in the variables of OT4 "since the position I hold has a low level, my notification of issue is not noticed" has a positive versatility effect at a rate of .84 in dimension of (OT) lack of experience.

When the fear of isolation dimension of organization silence attitude is analyzed, a one unit - rise in the variables of OIZ1 "Once I notified an issue, I may be evaluated to be a trouble maker / complaint” has a positive versatility effect at a rate of .83 in dimension of OIZ fear of isolation.

A one unit - rise in the variable of OIZ2 "notification of an issue may reduce the trust and respect felt to me" has a positive versatility effect at the 
rate of .80 in OIZ dimension and a one unit - rise in the variable of OIZ4 "Once I notified an issue, I may be evaluated to be a finger man / trouble maker” has a positive versatility effect at a rate of .84 in dimension of the fear of isolation.

While a 1 unit - rise in the variables of OIL1 "once I expressed the problems, my relations is exposed to damage" has an effect at a rate of .87 in dimension of (OIL) fear of damaging the relations, a 1 unit - rise in the variables of OIL2 “once I spoke clearly, people may not back me up" has a positive versatility effect at a rate of .77 and a 1 unit - rise in the variables of OIL3 “once I talked about issues or problems, my managers do not get pleased" at the rate of .80 in dimension of (OIL) fear of damaging the relation.

When the inter-dimensions relations of the organizational silence attitude are analyzed, it is seen that a one unit - rise in the relation of both dimensions of (OY) managerial and organizational causes and (OI) work related issues is effective for also both of them at a rate of .92.

When the relation between the dimensions of managerial and organizational causes are analyzed, it is seen that a one unit - rise in the relation of both dimensions of (OY) managerial and organizational causes and (OT) lack of experience has a positive versatility effect at a rate of .88 for both of them. When the relation between the dimensions of (OY) managerial and organizational causes and (OIZ) fear of isolation are reviewed, it is seen that a one unit - rise in both dimensions has a positive versatility effect at a rate of .89 for both of them. When the relation between the dimensions of (OY) managerial and organizational causes and (OIL) fear of damaging the relations are reviewed, it is seen that a one unit - rise in both dimensions has a positive versatility effect at a rate of .89 for both of them.

When the dimensions of (OI) work - related issues, (OT) lack of experience and the relation between them are reviewed, it is seen that a one unit - rise in both dimensions has a positive versatility effect at a rate of .87 for both of them and has a positive versatility effect at a rate of .93 versus (OIL) fear of damaging the relations.

When the dimensions of (OT) lack of experience, (OIZ) fear of isolation and the relation between them are reviewed, it is seen that a one unit - rise in both dimensions has a positive versatility effect at a rate of .92 for both of them and .93 versus the dimension of (OIL) damaging the relations.

Finally, when the relation between the dimensions of (OIZ) fear of isolation and (OIL) fear of damaging the relations are scrutinized, it is seen that a one unit - rise in both dimensions has a positive versatility effect at a rate of .96 for both of them. 


\section{Discussion, Conclusion and Suggestions}

Within the extent of this study, the concept of organization silence has been scrutinized under five factors "managerial and organizational causes", "work - related issues", "lack of experience”, "fear of isolation” and "fear of damaging the relations" and the relation and their variables and correlation between them and correlations between each other factors have been assessed.

It has been observed that all variables staying inside the dimension of managerial and organizational causes has a positive versatility effect on the dimension. A one unit - rise in both as per variables has an effect at the rates between .68 and .84. When the variables are reviewed, it is observed that the variables with the greatest influence are respectively "there is no formal mechanism which would allow me speak clearly, I think that the managers would not be all ears"; "I know the best attitude of my managers makes my speaking meaningless";

"My managers do not support my clearly speaking" and "I do not tell my problems since I do not trust my manager". In his study where he has researched organizational silence perception of the teaching elements functioning from the university, Ruclar (2013) has concluded that the dimension explanatory rates of the same variables are high. Also in this study, it has been seen that the similar expressions possess high - factorial loads. In parallel to these findings, in a study accomplished by Aliogulları (2012), he has concluded that the behavior of employees showing remaining silent due to managerial and organizational reasons is related to mostly behaviors of manager like "employee does not trust her / his manager", "I know the best attitude of the managers", "non-consideration of employees' opinions" and "clearly talk at the workplace is not supported". Similarly, Botero and Dyne (2009, p. 88) have set forth that there was a positive versatility effect between the level of the management in being open to communication and the levels where the employees express themselves. In consequence the studies carried out by Vakola and Bouradas (2005, p. 441), also the finding oriented towards availability of an correlation between the managers - offered communication opportunities to the employees and silence perceptions of the employees is in nature of backing up the findings of this study as well. Being different from these findings, in the study carried out by Alpaslan (2010) together with the academic staff, he has acquired the findings that negative attitudes of the managers regarding the employees to express themselves and organizational communication opportunities do not have any effect on organizational silence behavior of the employees.

In (2010), Kahveci has set forth that in a similar way with the findings of this study, the average of the article $\{$ item $\}$ related to the 
employees who stay silent because of not feeling any trust to their managers was low in comparison to other items. Again according to the findings of this study, management's sincere and honest attitude has a positive effect on employees to share their thoughts and feelings. Once the employees did not express their ideas, affirmative feedbacks to come from the management may reduce silence attitudes of employees. Once these data were taken into consideration, the creation of a communication medium where the employees can express their ideas freely and the psychological confidence required to be provided for this and the managers care about the ideas of the employees are considered by the managers may allow to make comment of a reduction to happen in the organizational silence perception (Ruclar, 2013).

When the dimension of work - related issues was analyzed, it is seen that there is a positive versatility, high - level correlation between all variables and the dimension. It has been determined that a 1 unit - increase as per variable has an effect at the rates between .65 and .84. The findings of study have demonstrated that the variable with the highest effect on the dimension was "talking freely may result in to lose my job" and "new ideas and suggestions may enhance my workload” was the lowest variable. Also in the study of Ruclar (2013), in similar way, the positive and the highest level effect of the same variables on dimension have been observed. As for this study, it is seen that the variable having the greatest impact is "when I talk clearly, my manager or colleagues may be in a bad mood against me" and the lowest impact possessing variable is "Talking clearly may lead to lose my job". In the study carried out by Aliogulları in (2012), in a similar manner, he has revealed that "job loss" and "fear of place of work and position alteration" are contained in the foundation of work - related issues causing organizational silence in a similar way.

When the reasons of attitudes of staying silent based on the lack of experience by the employees are looked into, it is observed that the variables have a positive versatility and high - level correlation with dimension. It has been identified that a one unit - rise as per variables has an effect on dimension at the rates between .66 and .84. In addition to this, it is observed that the variable with the highest effect on dimension is "since the position I currently hold is of low level, my notification of an idea are not considered" and "I do not have sufficient experience to report a problem or make suggestion" and the problem related to my workplace and job new ideas interest the management, not me” is the lowest variable. Similarly, also in the study accomplished by Ruclar in (2013), the positive and normal effect of the same variables on dimension is observed. As for this research, it is observed that the variable with the highest effect is "the problem related to my workplace and job new ideas interest the management, not me" and the variable with the lowest effect is "The issue I express may reveal my 
ignorance and inexperience”. In his study of Ruclar (2013), it is observed that the tendency of being silent by the teaching elements increases as their functional terms and status in profession decreases and their tendency of staying silent decreases as their experience and status promotes. The studies in nature of supporting the findings of this study are contained in the literature (Kahveci, 2010; Near and Miceli, 1996). Nevertheless, in the study accomplished by Erenler (2010), he has reached at the finding that the seniority did not generate any difference on the attitude of organization silence.

When the reasons of employees' isolation fear - based behavior of remaining silent are analyzed, it has been observed that all variables contained in the questionnaire are associated with dimension at a positive versatility and high level. It has been identified that a one unit - rise as per variables has an effect on dimension at the rates between .82 and .84 . Similarly, also in the study accomplished by Ruclar in (2013), the positive and high - level effect of the same variables on dimension is observed. Unlikely, it has been determined that while the variable of "my manager reacts negatively to negative feedback" has the least effect on dimension in this study, such variable in the study of Ruclar (2013) has the highest effect on dimension. Again, in parallel to the findings of this study of Aliogulları (2012), the causes underlying the fear of being isolated from environment of employees has been determined to be "to undergo the fear of loss of trust and respect" and "being considered as a trouble maker".

When the qualities of the variables contained within the dimension of fear of damaging the relations attitude regarding the organizational silence behavior are examined, it has been seen that three variables contained in this dimension have also a high and positive versatility effect on the dimension. The effect of a one unit - rise of the variables on the dimension varies between .87 and .77. Similarly, also in the study of Ruclar (2013), it has been observed a high - level and positive effect of the same variables on the dimension has been observed. However, unlikely "once I told the problems, my relations get damaged" is the highest effect - holding dimension comes along as the variable possessing the lowest effect in the study of Ruclar (2013). Similarly, in the outcomes of a study Sarioglu (2013) has accomplished together with the employees of a company operating in the energy sector, presence of a high and positive versatility effect related to similar variables in form of "to maintain my relations with my colleagues, I remain silent" and I prefer staying silent not to experience conflict" contained in protecting the relations - based silence dimension of the organizational silence scale consisting of two sub-dimensions has been identified. In a study carried out by Milliken and Morrison in (2003), they have reached at the finding that there is not a case in which disclosure of 
organization - related problems by the employees is not a situation liked by certain managers. In his study carried out by Aliogulları in (2012), in relation to the fear of damaging the relations, he has suggested that the employees remain silent due to the fear of "relations may be harmed" and post expression fear of losing support”.

In conclusion, in line with the modern management approaches, the most substantial source for the labor - intensive type of operations in reaching at their objectives can be expressed to be the human. In this context, utilization from the source of human at the most effective level from the hotel operations, presents significance. In the study, it may be said over a general framework that the hotel employees to be taken by the feelings; the managers would not care about their ideas, speaking clearly would make them lose their jobs, the stages they are in are insufficient for expressing an idea, reporting an issue would decrease the trust and affection felt, being assessed to a trouble maker, once they narrated or shared the problems, their relations would be harmed and when they spoke clearly, their colleagues would not support them has come out to be the effects of the organization silence.

Hotel business in the name of the managers of hotel operations not to come across these situations, following suggestions may be made; - To give importance to the idea of employees, - $\quad$ To create a system to operational structure of which the employees are involved and they can make their proposals and comments, - The managers to be constantly open to innovations, - $\quad$ Giving priority to individuality, not to see the employees as a loss of time,

- $\quad$ Rather than making up adverse sentences, a conciliatory approach to be adopted against the employees,

- $\quad$ Reducing the distance between the manager-employee,

- It can be said that non-consideration of critics made against the managers or work to be insolence at all, it can be said that assessment of them in such a way they would yield a positive impact on the operation in preventing the employees working at the hotel operations to get silent against organization would be effective in preventing silent on the organization.

Naturally, this study has some limitations and missing sides. However, due to having approached from the subdivision perspectives of organizational silence attitude, it covers an important gap in the literature. Execution of similar studies in future on this matter, particularly with much more distinctive mass of subjects would be the point. Accomplishment of similar studies in different sectors would let us comprehend the organizational silence better and thus, enable us to follow the strategies 
which might change the behaviors of employees of this nature in the positive direction.

\section{References:}

Argyris, C. (1977). Double Loop Learning in Organizations. Harvard Business Review, 55, 115-125.

Arslantaş, C. C. and Dursun, M. (2008). Influence of Trust to Ethical Leadership Behavior and Psychological Empowerment towards Mediating Role of Interactive Justice. Anadolu University Journal of Social Sciences, 8(1), 111-128

Alioğulları, Zişan Duygu. (2012). The Relationship Between Organizational Citizenship Behavior and Organizational Silence: A Study, (Unpublished Master Thesis), Ataturk University, Institute of Social Sciences, Erzurum.

Alparslan, A. M. (2010). Interaction Between Organizational Climate and Employee Silence Silence Behavior: A Study on Teaching Staff of Mehmet Akif Ersoy University, (Unpublished Master Thesis), Süleyman Demirel University Institute of Social Sciences, Isparta.

Barçin, Nafi. (2012). A Study on the Effect of Organizational Silence on Organizational Commitment and Job Satisfaction in Enterprises on the Effect, (Unpublished Master Thesis), Çukurova University Institute of Social Sciences, Adana.

Beheshtifar M., Borhani H., Moghadam M. N. (2012). Destructive Role of Employee Silence in Organizational Success. International Journal of AcademicResearch in Business and Social Sciences, 2(11), 275-282.

Bildik, Büşra. (2009). Leadership Styles, Relationship between Organizational Commitment and Organizational Silence, (Unpublished Master Thesis), Gebze High Technology Institute, Kocaeli.

Botero, Isabel C. and Linn Van Dyne. (2009). Employee Voice Behavior Interactive Effects of LMX and Power Distance in the United States and Colombia. Management Communication Quarterly, 23(1), 84-104.

Bowen, Frances and Kate Blackmon. (2003). Spirals of Silence: The Dynamics Effects of Diversity on Organizational Voice. Journal of Management Studies, 40(6), 1393-1417.

Brinsfield, C. T. (2009). Employee Silence: Investigation of Dimensionality, Development of Measures and Examination of Related Factors Dissertion. (Unpublished Ph.D Dissertation). USA: Ohio StateUniversity.

Bryant, Melanie and Julie Wolfram Cox. (2004). Conversion Stories as Shifting Narratives of Organizational Change, Journal of Organizational Change Management, 17(6), 578-592.

Çakıcı, A. (2007). Organizational Silence: Theoretical Basics and Dynamics of Silence. Canakkale University Journal of Institute of Social Sciences, 16 (1), 145-162. 
Çakıc1, A. (2010). Organizational Silence in Organizations: Why Do We Prefer to Remain Silent?. Ankara, Detay Publishing, First Press.

Çakıc1, A. and Çakıcı, A.C. (2007). A Study on Issues Employees Clearly Want to Talk with the Leaders. Proceedings of 16th National Congress of Management and Organization, Mehtap Gülaçtı (Ed.), (p. 330-334). Istanbul: IKU Publications.

Detert, J.R.,Edmondson, A.C. (2005). No Exit, No Voice: The Blind of Risky Voice Opportunaties in Organizations. Academy of Managemenet Proceedings, 1-6.

Dyne, Linn Van, Soon Ang and Isabel C. Botero. (2003). Conceptualizing Employee Silence and Employee Voice as Multidimensional Constructs. Journal of Management Studies, 40(6), 1359-1392.

Erenler, Esra. (2010). The Relationship of Silence Behavior of the Employees between Some Personal and Organizational Traits: A Field Survey in Tourism Sector, (Unpublished Ph.D Dissertation), Hacettepe University, Institute of Social Sciences, Ankara.

Erçelik, E. (2008). Evaluation of Organizational Communication in terms of Employee Productivity. (Unpublished Master Thesis), Pamukkale University Institute of Social Sciences, Denizli.

Fletcher, Denise and Tony Watson. (2007). Voice, Silence and the Business of Construction: Loud and Quiet Voices in the Construction of Personal Organizational and Social Realities, Organization, 14(2), 155-174.

Huang, Xu, Evert Van de Vliert and Gerben Van der Vegr. (2005). Breaking the Silence Culture: Stimulation of Participation and Employee Opinion Withholding Crossnationally. Management and Organization Review, 1(3), 459-482.

Henriksen, Kerm and Elizabeth Dayton. (2006). Organizational Silence and Hidden Threats to Patient Safety, Health Services Research, 41(4), 15391554.

Kahveci, G. (2010). Relationships between Organizational Commitment Organizational Silence in Primary Schools. (Unpublished Master Thesis). Firat University Institute of Social Sciences. Elazığ

Karadal, Himmet (2011). Organizational Silence Behavior and Its Influences, in Individual and Organizational Based Behavior in Management, Özcan Yeniçeri, Yavuz Demirel (Eds), 1. Press, Ekin Publications, Bursa.

Liu, D.,Wu, J. and Ma, J. (2009). Organizational Silence: A Survey on Employees Working in a Telecommunication Company. Computers \& Industrial Engineering International Conference, 1647-1651.

Milliken, F.J. \& Morrison, E.W. (2003). Shades of Silence: Emerging Themes and Future Directions for Research on Silence in Organizations. Journal of Management Studies, 40 (6), 1563-1568. 
Morrison, Elizabeth W. and Frances J. Milliken. (2000). Organizational Silence: A Barrier to Change and Development in a Pluralistic. The Academy of Management Review, 25(4), 706-714.

Milliken, Frances J., Elizabeth W. Morrison and Patricia F. Hewlin. (2003). An Exploratory Study of Employee Silence: Issues that Employees Don't Communicate Upwardand Why?, Journal of Management Studies, 40(6), 1453-1476.

Near, J. P. and Miceli, M. P. (1996). Whistle - Blowing: Myth and Reality, Journal of Management, 22(3), 507526.

Oruç, M. (2013). The Relationship between Organizational Commitment and Silence: A Study in a Firm, Marmara University Institute of Social Sciences, Istanbul.

Özdemir, L., and Sarıŏlu Uğur, S. (2013). Evaluation of Organizational Voice and Silence Perceptions of the Employees in terms of Demographic Characteristics. A Survey of Public and Private Sector. Atatürk University Journal of Faculty of Economics, 27(1), 257-281.

Pinder, C. C. and Harlos, K. P. (2001). Employee Silence: Quiescence and Acquiescence as Responses to Perceived Injustice. Research in Personnel and Human Research Management, 20, 331-369.

Podsakoff, P. M., MacKenzie, S. B., Paine, J. B. and Bachrach, D. G. (2000). Organizational Citizenship Behaviors: A Critical Review of the Theoretical and Empirical Literature and Suggestions for Future Research. Journal of Management, 26 (3), 513-563.

Premeaux, Sonya Fontenot, (2001). Breaking the Silence: Toward an Understanding of Speaking up in the Workplace, (Unpublished Ph.D Dissertation), Louisiana State University, USA.

Premeaux, Sonya Fontenot and Arthur G. Bedeian. (2003). Breaking the Silence: The Moderating Effects of Self-Monitoring in Predicting Speaking Up in the Workplace. Journal of Management Studies, 40(6), 1537-1562.

Rafferty, Alannah E. and Simon Lloyd D. Restubog. (2011). The Influence of Abusive Supervisors on Followers' Organizational Citizenship Behaviours: The Hidden Costs of Abusive Supervision. British Journal of Management, 22, 270-285.

Ruçlar, K. (2013). The Relationship between Organizational Culture and Organizational Silence- Example of Sakarya University, (Unpublished Master Thesis), Sakarya University Institute of Education Sciences, Sakarya. Quinn, Robert E. And Gretchen M. Spreitzer. (1997). The Road to Empowerment: Seven Questions Every Leader Should Consider, Organizational Dynamics, 26(2), 37-49.

Sarıkaya, M., (2013). Decision-making Processes and Organizational Silence, (Unpublished Master Thesis), Pamukkale University Institute of Social Sciences, Denizli. 
Sarığlu, G. Ş. (2013). Mobbing and Organizational Silence: A Study on the Energy Sector Workers, (Unpublished Master Thesis), Osmaniye Korkut Ata University Institute of Social Sciences, Osmaniye.

Scheufele, D. A. and Moy, P. (2000). Twenty-fiveyears of the spiral of silence: A Conceptual review and Empirical Outlook. International Journal of Public Opinion Research, 12, 3-28.

Slade, Michael Ross (2008). The Adaptive Nature of Organizational Silence: A Cybernetic Exploration of the Hidden Factory, (Unpublished Ph.D Dissertation), George Washington University, USA.

Soycan, Hande Ş. (2010). The Relationship between Organizational Commitment and Organizational Silence after Merger of Banks, (Unpublished Master Thesis), Marmara University Institute of Social Sciences, Istanbul.

Şehitoğlu, Y. (2010). The Relationship among Organizational Silence, Organizational Citizenship and Perceived Employee Performance. (Unpublished Ph.D Dissertation), Gebze Institute of High Technology. Gebze.

Şehribanoğlu, S. (2005). Structural Equation Modeling and A Research, (Master Thesis), Yüzüncü Y1l Universiy Institute of Applied Sciences, Van. Taşkıran, Erdal. (2011). Interaction between Leadership and Organizational Silence. Istanbul.1. Press, Beta Publications

Vakola, Maria and Dimitris Bouradas. (2005). Antecedents and Consequences of Organizational Silence: An Emprical Investigation. Employee Relations, 27(5), 441-458.

Yanık, Canan. (2012). The Relationship Between Organizational Silence and Trust: A Research in Educational Organizations, (Unpublished Master Thesis), Yeditepe University, Istanbul.

Yilmaz, V., Çelik, H. E. (2009). Structural Equation Modeling I, Ankara, Anı Publications.

Yılmaz, V., Çelik, H. E. (2005). Customer Satisfaction in Banking Sector and Investigation of Loyalty to Bank Sector via Structural Equation Model, VII. National Symposium on Econometrics and Statistics, Istanbul University, 26-27 May 2005. 